\title{
Modelagem e análise de um novo centro cirúrgico para um hospital em crescimento: uma abordagem baseada em simulação
}

\author{
Élcio Douglas Joaquim PUCPR \\ Guilherme Ernani Vieira PUCPR
}

\section{RESUMO}

Uma instituição hospitalar precisa de constante aperfeiçoamento para ser eficiente no seu principal negócio: o bem-estar do ser humano. Este artigo descreve um projeto realizado no Hospital Universitário da PUCPR, cujo principal objetivo é avaliar alterações no Centro Cirúrgico com o intuito de se preparar melhor para o aumento de demanda esperado para os próximos anos. Foram simulados e analisados quatro novos cenários, os quais incluíram restruturação de atividades de atendimento e ampliação do número de salas cirúrgicas. Os modelos de simulação mostraram que em geral as alterações sugeridas trarão benefícios ao centro e que o melhor cenário deverá ter duas novas salas de cirurgia e uma restruturação das atividades internas do centro. Isto reduzirá o tempo de espera do paciente por sala cirúrgica e também a própria taxa de ocupação das salas, além de atender bem à comunidade até 2010/2011.

\section{Modeling and analysis of a new surgical center for a growing hospital: a simulation-based approach}

\begin{abstract}
A hospital institution needs frequent improvement to be efficient at its core business: the care of the human being. This paper describes a project conducted at PUCPR's University Hospital, which main objective is to evaluate changes to the Surgical Center aiming at being better prepared for the demand increase expected for the coming years. Four new scenarios were simulated and analyzed, which included restructuring of internal activities and the increase on the number of surgical rooms. The simulation models showed that the suggested changes will benefit the center and that the best scenario should have two new surgical rooms along with the restructuring of the internal activities flow. This will reduce the patient waiting time for surgical room and the rooms' utilization, besides providing a good service to the community until 2010/2011.
\end{abstract}

\section{KEY WORDS}

Hospital processes; surgical center; simulation. 


\section{INSTITUIÇÕES HOSPITALARES PRECISAM SER EFICIENTES}

Como as empresas de manufatura, as instituições hospitalares também precisam buscar constantemente ferramentas que possibilitam a melhoria da qualidade dos seus serviços, visando se manter nos patamares de competitividade atualmente exigidos. Embora muitos hospitais sejam instituições filantrópicas e/ou públicas, a busca constante por alternativas que possam melhorar seus processos para oferecer atendimento de qualidade ao maior número possível de pacientes, em um contexto de investimentos financeiros limitados, é uma necessidade real e constante.

Neste contexto, um dos primeiros passos para que se otimize o uso dos recursos existentes em um hospital é a análise e, quem sabe, reorganização da sua atual estrutura funcional, com o auxílio da tecnologia de informação, sem perder de foco custos e sem prejudicar o desempenho e a qualidade dos serviços prestados à sociedade. Por tratar do bem-estar e saúde de pessoas, processos hospitalares devem estar bem estruturados para que pacientes sejam atendidos com qualidade e no menor tempo possível.

Uma instituição hospitalar também deve estar preparada para os aumentos de demanda esperados. Barros e Sena (1998) constataram, por exemplo, que ampliações na infraestrutura de atendimento dos hospitais, com o objetivo de atender o crescente aumento de demanda, apresentaram um aumento de custo desproporcional ao aumento do volume de atendimento (que se caracteriza em receita ao hospital). Ou seja, não se conseguiu obter economia de escala na prestação dos serviços. Abel-Smith (1996) afirma também que não é possível obter economia de escala quando hospitais funcionam com uma taxa de ocupação inferior a $70 \%$ e sugere que, nestes casos, a solução viável, embora politicamente impopular, é fechar parte do hospital.

Longe de significarem um desestímulo em investir na infra-estrutura de saúde, esses trabalhos reforçam a ideia de que investimentos precisam ser acompanhados de técnica $\mathrm{e}$ método adequados, fazendo uso, por exemplo, de ferramentas que possam avaliar com eficiência o retorno dos recursos aplicados. Simulação computacional pode contribuir para tais análises e tomadas de decisão.

Neste projeto, simulação computacional é usada como ferramenta de análise para um novo Centro Cirúrgico do Hospital Universitário Cajuru (CCHUC), da Pontifícia Universidade Católica do Paraná. Quatro novos cenários serão analisados com o objetivo de se descobrir a melhor configuração para o novo centro cirúrgico, de forma a se lidar com o aumento de demanda esperado. Assim, no total, cinco cenários serão modelados e simulados. O primeiro a ser desenvolvido representará o cenário atual, seu objetivo é comprovar que os resultados reais atuais podem ser repetidos em um modelo de simulação. As outras quatro configurações representarão possíveis alternativas para o novo centro. As propostas a serem analisadas serão:

1. Cenário proposto I - considera somente as alterações no fluxo de atividades internas ao centro, mantendo o mesmo número de salas de cirurgia;

2. Cenário proposto II - prevê o aumento no número de salas de cirurgia (de seis para dez), mantendo o fluxo atual das atividades cirúrgicas;

3. Cenário proposto III - considera ambas as alterações possíveis, isto é, mudanças no fluxo de atividades e aumento do número de salas de cirurgia (seis para dez). Espera-se que este cenário traga as melhores respostas, entretanto, este cenário possivelmente não será implantado devido ao alto custo financeiro necessário. Para minimizar os custos desta opção, propõe-se uma configuração parecida com este cenário III, só que mais barata:

4. Cenário poposto IV - exatamente igual ao Cenário III mas com um aumento de apenas duas salas de cirurgia (total de oito salas cirúrgicas) aliado à reconfiguração dos fluxos de atividades internas do centro (II + III).

\section{timize o uso dos recursos existentes em um hospital com o auxílio da tecnologia de informação, sem perder de foco custos e sem prejudicar o desempenho e a qualidade dos serviços.}

Este artigo está organizado da seguinte maneira: A próxima seção revisa alguns trabalhos encontrados na literatura que aplicam simulação computacional em instituições hospitalares. A seção 3 descreve o ato cirúrgico e o atual Centro Cirúrgico do Hospital Universitário Cajuru. A seção 4 mostra como foi executado o projeto de melhoria no atual centro cirúrgico, seu modelo de simulação e os resultados para validação do modelo. A seção 5 descreve os cenários propostos, os modelos desenvolvidos e os resultados experimentais obtidos. Nesta seção, faz-se também uma comparação dos cinco cenários analisados. A seção 6 traz alguns comentários finais e faz algumas sugestões para trabalhos futuros. 


\section{SIMULAÇÃO EM INSTITUIÇÕES HOSPITALARES E CENTROS CIRÚRGICOS}

O uso da simulação no setor hospitalar ainda é modesto, entretanto, alguns trabalhos já relatam os sucessos e benefícios dessa tecnologia neste setor. Perdoná et al. (2003), por exemplo, aplicaram simulação para estimar a ocupação de recursos, o dimensionamento de filas e tempos produtivos. Borba e Rodrigues (1998a e 1998b) apresentam uma pesquisa realizada com os hospitais da região metropolitana de Porto Alegre, onde se buscou observar o conhecimento e o interesse dos hospitais na ferramenta. Neste foi constatado que $82 \%$ dos entrevistados já tinham ouvido algo sobre simulação e, quando questionados sobre quais seriam os benefícios sobre o seu uso, os mais citados foram:

- Melhor alocação de recursos.

- Agilizar serviços e tomada de decisão.

- Melhorar a qualidade do atendimento.

- Traçar alternativas para a resolução de problemas.

- Análise de investimentos.

- Redução de desperdícios e gastos desnecessários.

- Identificação de restrições no sistema.

Sanches et al. (2000) afirmam que a simulação pode auxiliar pelo menos quatro áreas no contexto hospitalar: previsão de demanda (volume de pacientes a serem atendidos), análise de padrão de desempenho, dimensionamento de recursos (layout, número de salas, equipamentos) e dimensionamento de equipes de atendimento. Como os departamentos de atendimento de emergência dos hospitais trabalham normalmente com uma quantidade limitada de recursos, tanto de pessoal como de equipamentos e materiais, o tempo de espera e o tempo que o paciente permanece no sistema são elevados (MILLER et al., 2003) - a simulação pode auxiliar hospitais a melhorar a utilização dos recursos de forma a minimizar tais tempos.

Osidach e Fu (2003) utilizaram simulação para determinar qual layout e composição de equipe de atendimento apresentaria os maiores benefícios e os menores custos para uma central móvel de exames que atua no controle e prevenção de doenças e saúde dental nos Estados Unidos. Foram testadas seis combinações de cenários, variando-se a quantidade de técnicos de saúde e a quantidade de pacientes atendidos por técnico. Experimentos de simulação mostraram que a configuração ótima deveria utilizar três técnicos, com média de sete atendimentos por técnico.

De acordo com Brady (2003), após o atentado terrorista de 11 de setembro, verificou-se a necessidade de se elaborar um plano de atendimento às vítimas desse tipo de incidente.
Construiu-se um modelo de simulação que utiliza como variáveis de entrada a hora da ocorrência, a localização, o número de pessoas diretamente afetadas e o efeito de latência (um atentado que utilize agentes químicos ou biológicos causará efeitos após a hora de ocorrência, diferentemente de uma explosão, que o efeito é imediato). De acordo com a combinação das variáveis de entrada, serão acionados diferentes planos de ação, que preveem acionamento de polícia, bombeiros, ambulâncias, locais para destino das vítimas, médicos, enfermeiros, equipamentos e materiais para cuidado das vítimas, etc.

Blasak et al. (2003) utilizaram simulação computacional com o objetivo de reduzir o tempo de permanência de pacientes na unidade de emergência do Rush North Shore Medical Center e analisar os requisitos para melhorar a interação entre a unidade de emergência e a UTI. As sugestões existentes como alternativas de melhoria seriam: designar uma enfermeira dedicada a efetuar a triagem dos pacientes admitidos na unidade de emergência, informar a unidade de emergência imediatamente quando um leito de UTI está liberado e ampliar a quantidade de leitos na UTI. As alternativas foram testadas no modelo, e como conclusão verificou-se que a redução do tempo de permanência do paciente na unidade de emergência poderia ser alcançada adotando-se determinadas medidas.

Barnes e Quiason (1997) relatam que no University Hospital and Medical Center at Stony Brook (New York, EUA), a simulação foi usada na remodelagem do setor de atendimento a procedimentos pré-operatórios. Este setor é responsável por efetuar exames em pacientes que foram indicados por seus médicos para sofrerem uma intervenção cirúrgica. A simulação foi indicada para esse caso devido ao potencial impacto de redução de custos na qualidade do serviço a ser prestado ao paciente e à dúvida existente na especificação do projeto. Através da simulação, pôde-se identificar o cenário com os melhores resultados de custo e qualidade.

No Brigham and Women's Hospital (Boston, EUA), Lowery e Davis (1999) utilizaram simulação para determinar a quantidade de salas de cirurgia necessárias para atender à crescente demanda da instituição. Inicialmente o projeto previa a necessidade de 32 salas de cirurgia. Após a validação do cenário existente, foram propostos novos cenários onde se concluiu que 30 salas seriam suficientes para atender ao fluxo da organização.

Ramis et al. (2001) apresentaram um estudo realizado na Universidad Del Bio-Bio (Concepción,Chile), onde foi utilizada simulação para avaliar diferentes alternativas para a implantação de um Centro Cirúrgico (CC) ambulatorial destinado à realização de pequenos procedimentos, o que 
reduz o fluxo de pacientes no hospital. Como conclusão desse trabalho, obteve-se um cenário otimizado onde se definiu: um novo layout a ser implantado, o número de leitos para a preparação dos pacientes e o número de leitos para a recuperação após o procedimento.

Denton et al. (2006) também fizeram um trabalho interessante sobre o agendamento em um centro cirúrgico da Mayo Clinic (Rochester, EUA). Neste trabalho eles apresentaram um modelo de simulação para um centro cirúrgico com múltiplas salas de cirurgia. Descreveram alguns dos desafios inerentes aos problemas de agendamento e ilustraram como o modelo pode ser usado como uma ferramenta de auxílio para melhorar a tomada de decisões estratégicas e operacionais relacionadas à execução de procedimentos cirúrgicos.

Cardoen e Demeuleneester (2007) analisaram trajetórias de pacientes usando caminhos clínicos e agregaram esses fatores em um modelo de simulação discreta. Este modelo ajuda a gerência de uma instituição hospitalar a avaliar e melhorar importantes indicadores de desempenho, tanto para o paciente quanto para o hospital, através da condução de análises de sensibilidade. Estudos de caso foram realizados em dois grandes hospitais em Antwerp e Leuven (Bélgica).

\section{ENTENDENDO O ATO CIRÚRGICO E AS PROPOSTAS DE MELHORIAS PARA O CCHUC}

Um procedimento operatório executado no CCHUC divide-se em seis processos básicos: agendamento, programação, pré-operatório, trans-operatório, pós-operatório e encaminhamento (HUC, 2002). Entretanto, este projeto concentra-se apenas no "trans-operatório" (Figura 1) por ser o processo chave no centro, incluindo o ato cirúrgico propriamente dito, e por ser o processo que pode trazer os maiores benefícios à instituição.

Com o intuito de atender à crescente demanda, já existe no HUC um projeto em andamento que prevê a ampliação do número de salas de cirurgia e também a alteração no fluxo das atividades realizadas dentro destas salas. Este projeto faz uma estimativa mais precisa da capacidade de atendimento e do novo layout que o CCHUC deverá adotar, bem como a verificação de alternativas que poderiam aumentar a capacidade de atendimento com o menor investimento, frente a diferentes níveis de aumento de demanda.

De acordo com HUC (2001), o Centro Cirúrgico fun- ciona ininterruptamente para o atendimento às cirurgias de emergência. Já as cirurgias eletivas são agendadas de segunda a sexta-feira em três turnos e nos sábados em dois turnos. Devido a essa regulamentação, constata-se que nos feriados, finais de semana e após as 22 horas, a taxa de ocupação do CC não é crítica, pois não ocorre a concorrência de cirurgias eletivas. Por estes motivos, considerou-se somente o movimento em dias úteis e no período das seis horas da manhã até às 22 horas. Nesse período são realizadas aproximadamente $80 \%$ do total de cirurgias.

\section{nvestimentos precisam ser acompanhados de técnica e método adequados, fazendo uso, por exemplo, de ferramentas que possam avaliar com eficiência o retorno dos recursos aplicados.}

As cirurgias de emergência possuem prioridade em relação às cirurgias eletivas. Normalmente a sala número um é reservada para esse tipo de cirurgia, porém tendo disponibilidade ela também pode ser utilizada para cirurgias eletivas. Caso a sala um esteja ocupada e for necessário executar um procedimento de emergência, será utilizada qualquer outra sala que esteja liberada. Se as demais salas estiverem reservadas para cirurgias eletivas, verifica-se qual oferece menor impacto para que seja atrasada ou reagendada para uma outra data.

O fluxo de atendimento ao paciente para execução do procedimento cirúrgico é composto das seguintes etapas (subprocessos):

- Preparação: esta etapa começa com a recepção do paciente na sala de cirurgia.

- Anestesia: o tempo desta etapa é computado a partir do momento em que se inicia a indução anestésica até o momento do início do procedimento cirúrgico.

- Cirurgia: nesta etapa registra-se o tempo da intervenção cirúrgica.

- Término da anestesia: essa fase compreende o momento em que o cirurgião encerra o seu procedimento, até o momento em que cessa a indução anestésica e o paciente é extubado.

- Alta de sala: após a conclusão da anestesia o paciente recebe acompanhamento, ainda na sala de cirurgia, até que ocorra o retorno dos reflexos, quando então ele é retirado da sala operatória.

- Limpeza: este é um procedimento que não afeta diretamente o paciente, porém é computado no modelo por afetar diretamente o tempo de ocupação da sala. 


\section{MODELAGEM E ANÁLISE DO ATUAL CENTRO CIRÚRGICO}

As informações referentes aos procedimentos cirúrgicos foram obtidas através de registros em arquivos, documentação administrativa e entrevistas com funcionários do centro no período de 1 de fevereiro a 31 de março de 2004. Especificamente, foram coletadas as seguintes informações sobre cada procedimento cirúrgico: (a) Sala utilizada; (b) Data do procedimento; (c) Tipo de cirurgia (emergência ou eletiva); (d) Especialidade (geral, neurologia, ortopedia e outros); (e)
Hora de entrada do paciente na sala; (f) Hora do início da anestesia; (g) Hora do início da cirurgia; (h) Hora do término da cirurgia; (i) Hora do término da anestesia; e (j) Hora da saída do paciente da sala.

\subsection{Análise dos dados coletados}

A primeira variável a ser analisada refere-se à distribuição do intervalo de tempo entre chegadas de pacientes ao centro cirúrgico. Considerou-se o uso do centro cirúrgico somente nos dias úteis e no período das 6:00 às 22:00 horas por ser o horário mais crítico, ocorrendo tanto cirurgias de emer-

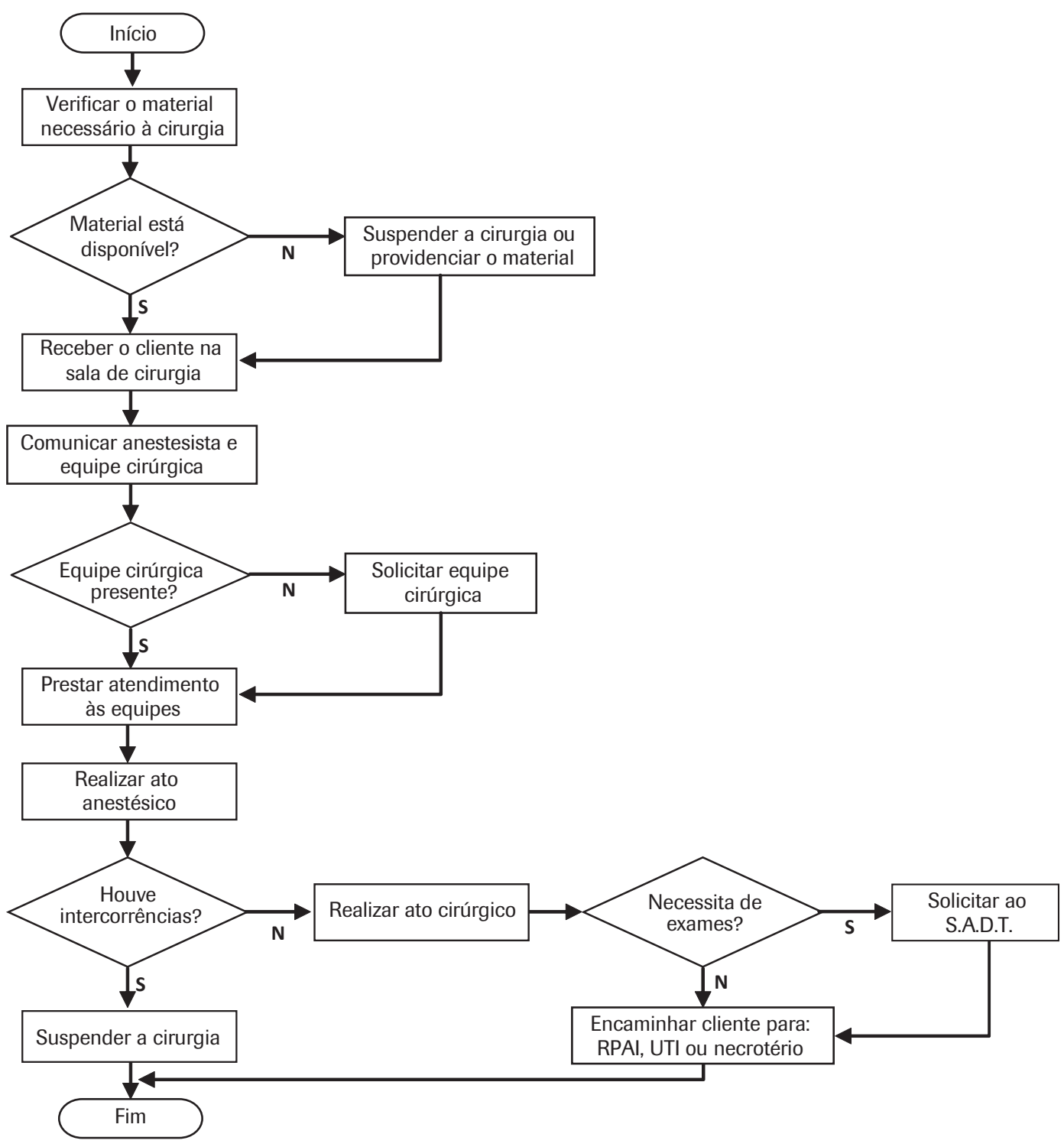

Figura 1: Processo trans-operatório.

Fonte: HUC, 2002 
gências quanto eletivas. Cabe ressaltar que entre o horário de 19:00 e 22:00 horas são realizadas apenas 7\% do total de cirurgias eletivas e $17 \%$ do total de cirurgias de emergência. A Tabela 1 mostra os tempos médios e semi-intervalos de confiança do tempo entre chegadas de pacientes.

Tabela 1: Tempo entre chegadas de pacientes.

\begin{tabular}{ccc}
\hline Tipo de cirurgia & Média (min) & Semi-Intervalo (min) \\
\hline Eletiva & 70,38 & 7,00 \\
Emergência & 126,36 & 12,81 \\
\hline
\end{tabular}

Ao se analisar o intervalo de confiança (IC) calculado para cada tipo de cirurgia (Figura 2), percebe-se que eles não se sobrepõem e, portanto, tais variáveis devem ser tratadas como distintas (terão distribuições probabilísticas próprias).

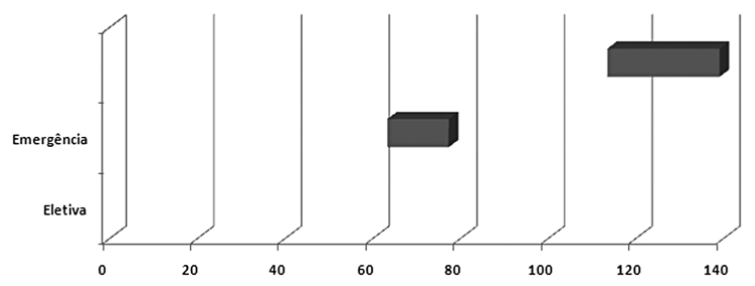

Figura 2: ICs para o tempo entre chegadas de pacientes.

Considerando que os procedimentos cirúrgicos são diferenciados de acordo com a especialidade, é importante analisar se existe variação de tempo de execução para cada especialidade médica considerada. As especialidades com maior ocorrência nas amostras são, em ordem decrescente, a especialidade de ortopedia (57\%), cirurgia geral (34\%) e neurologia (3\%). As outras dez especialidades somadas correspondem aos aproximados 6\% restantes. Diante dessa constatação, o conjunto de dados obtido foi agrupado considerando a especialidade como característica comum às seguintes amostras: cirurgia geral, neurologia, ortopedia e outras. Definidas as amostras, deve-se, então, calcular os intervalos de confiança para cada atividade executada no fluxo de atendimento. A Tabela 2 apresenta os valores dos ICs dos tempos de execução das atividades executadas na sala de cirurgia calculados para as especialidades e o tempo total de ocupação de sala também para as especialidades estudadas. A Figura 3 apresenta os respectivos gráficos.

Analisando-se os valores referentes aos intervalos de confiança dos tempos das atividades do fluxo de atendimento do centro cirúrgico, percebe-se que em sua maioria os intervalos coincidem, não se podendo afirmar com $95 \%$ de certeza que eles sejam diferentes (adotou-se 95\% como nível de confiança neste projeto). A única exceção foi a etapa de anestesia, em que se obtiverem intervalos de confiança diferentes para as especialidades de cirurgia geral e ortopedia. Entretanto, também se pode constatar que a especialidade de neurologia e o agrupamento denominado "outras" possuem um intervalo bastante amplo.

A amplitude do intervalo é inversamente proporcional ao tamanho da amostra, ou seja, quanto menor a amostra, maiores serão os limites do intervalo de confiança. Assim, julga-se necessário manter as amostras agrupadas por especialidade, visando dar maior representatividade ao modelo de simulação.

\subsection{Construindo modelo do cenário atual}

Para o tempo entre chegada de pacientes para realização de cirurgias, obteve-se tanto para cirurgias eletivas quanto de emergência a distribuição exponencial com média 70,4 minutos e 126 minutos, respectivamente. É importante salientar que todas as análises estatísticas, de modelagem e de simulação foram feitas no software Arena e seu respectivo analisador de dados (Input Analyzer).

A distribuição das quantidades de cirurgias foi efetuada de acordo com o percentual de cada uma pelo total de cirurgias que entram no sistema. Essa distribuição é diferenciada de acordo com o tipo de cirurgia e está apresentada na Tabela 3.

\section{modelo de simulação do cenário atual precisa ser validado para que se tenha confiabilidade nos resultados experimentais e, na sequência, possa-se fazer conjecturações e análises em cenários alternativos.}

A variável de tempo de uso das salas cirúrgicas por especialidade compreende os tempos de execução das tarefas desde a entrada do paciente na sala de cirurgia até o momento em que ocorre a limpeza desta, quando, então, a sala estará disponível para a realização de um novo procedimento cirúrgico. Não existe, para cada execução, o registro dos tempos gastos na tarefa de limpeza das salas. Como esta atividade não possui variação dependente do tipo nem da especiali- 
dade da cirurgia, considerou-se, com base na experiência dos executores dessa atividade, como sendo uniformemente distribuído entre 10 e 30 minutos. Analisando-se os tempos de execução das demais etapas do fluxo de atividades da sala operatória, obtiverem-se as distribuições de probabilidade apresentadas na Tabela 4. (Cabe lembrar que se utilizou o software estatístico Input Analyzer, o qual utiliza o erro Quadrático e os testes Chi Quadrado e Kolmogorov-Smirnov (KS) para encontrar a melhor distribuição probabilística para os dados de entrada.)

A Figura 4 mostra o modelo de simulação do cenário atual criado no software Arena (detalhes específicos de implementação não foram descritos para manter a concisão do artigo).

\subsection{Significância e comparações de desempenho}

Para realização dos experimentos de simulação é importante definir o número de replicações necessárias com base em um determinado nível de confiança (adotou-se 95\%). Para tal, usou-se um método baseado em Law e Kelton (1991) o qual mostrou que pelo menos 95 réplicas deveriam ser usadas. Adotou-se então 100 replicações.

As variáveis (indicadores de desempenho) utilizadas nas análises serão:

a. Tempo de espera por sala cirúrgica - cirurgia de emergência (KPI1).

b. Quantidade de cirurgias na fila de espera - cirurgia de emergência (KPI2).

c. Tempo total do paciente no sistema - CCHUC (KPI3). d. Taxa de ocupação média das salas de cirurgia (ocupação do CCHU): percentual do tempo em que cada sala de cirurgia permanece ocupada por um procedimento cirúrgico $\left(\mathrm{KPI}_{4}\right)$.

e. Percentual de cirurgias de emergência realizadas por dia (das 6:00 às 22:00) - KPI .

f. Percentual de cirurgias eletivas realizadas por dia (das 6:00 às 22:00) $-\mathrm{KPI}_{6}$.

As comparações de desempenho entre os cenários serão feitas através de teste de hipóteses. Os resultados serão obtidos na forma de intervalos de confiança: $I C=$ média \pm semi-intervalo. Quando há sobreposição dos intervalos de uma grandeza, diz-se que não se pode afirmar que há diferença entre elas, dentro de um nível de confiança de $95 \%$. Caso contrário, pode-se afirmar com $95 \%$ de certeza que as grandezas são diferentes.

O primeiro nível hierárquico do modelo no Arena está mostrado na Figura 5.

Tabela 3: Distribuição de cirurgias por especialidade

\begin{tabular}{ccc}
\hline Especialidade & Cirurgia eletiva & Cirurgia de emergência \\
\hline Cirurgia Geral & $32 \%$ & $35 \%$ \\
Neurologia & $3 \%$ & $3 \%$ \\
Ortopedia & $58 \%$ & $57 \%$ \\
Outros & $7 \%$ & $5 \%$ \\
\hline
\end{tabular}

Tabela 2: Tempos de uso de sala (em minutos).

\begin{tabular}{|c|c|c|c|c|c|}
\hline \multirow[t]{2}{*}{ Atividade } & & \multicolumn{3}{|c|}{ Especialidade } & \multirow[b]{2}{*}{ Outras } \\
\hline & & Cirurgia Geral & Neurologia & Ortopedia & \\
\hline \multirow[t]{2}{*}{ Preparação } & Média & 10,97 & 9,56 & 10,16 & 8,10 \\
\hline & Semi-intervalo & 1,72 & 4,92 & 1,18 & 3,19 \\
\hline \multirow[t]{2}{*}{ Anestesia } & Média & 20,42 & 34,09 & 27,55 & 21,62 \\
\hline & Semi-intervalo & 1,71 & 13,22 & 2,40 & 4,22 \\
\hline \multirow[t]{2}{*}{ Cirurgia } & Média & 86,25 & 154,78 & 89,39 & 76,31 \\
\hline & Semi-intervalo & 8,04 & 76,19 & 6,54 & 24,03 \\
\hline \multirow[t]{2}{*}{ Término de anestesia } & Média & 14,24 & 10,77 & 11,34 & 10,54 \\
\hline & Semi-intervalo & 2,80 & 2,42 & 1,14 & 3,27 \\
\hline \multirow[t]{2}{*}{ Alta de sala } & Média & 13,64 & 13,57 & 17,35 & 17,74 \\
\hline & Semi-intervalo & 2,54 & 8,32 & 9,44 & 14,59 \\
\hline \multirow[t]{2}{*}{ Total } & Média & 131,40 & 207,17 & 139,29 & 117,88 \\
\hline & Semi-intervalo & 9,27 & 79,88 & 8,93 & 29,60 \\
\hline
\end{tabular}




\subsection{Validação do modelo de simulação do cenário atual}

O modelo de simulação do cenário (situação) atual precisa ser validado para que se tenha confiabilidade nos resultados experimentais e, na sequência, possa-se fazer conjecturações e análises em cenários alternativos. A Tabela 5 apresenta os valores obtidos para a quantidade média de cirurgias verificadas no cenário real, calculado diretamente dos dados coletados, e os valores calculados referentes ao número de cirurgias (cenário simulado).

Efetuando-se a análise comparativa dos intervalos de confiança para a variável quantidade de cirurgias por tipo, constata-se que os intervalos de confiança são coincidentes, tanto para as cirurgias eletivas quanto para as cirurgias de emergência. Pode-se então concluir que, com 95\% de certeza, o modelo de simulação representa o cenário real, pois gera resultados compatíveis com os resultados reais atuais do centro cirúrgico. Fez-se também uma análise (validação) considerando-se a quantidade média de cirurgias realizadas, conforme especialidade médica. Novamente, conforme ilustrado na Figura 6, o modelo de simulação criado representa significativamente $o$ atual centro cirúrgico.

Efetuando-se a análise comparativa dos intervalos de confiança para a variável quantidade de cirurgias por especialidade, constata-se que os intervalos de confiança são novamente coincidentes, creditando-se, mais uma vez, a confiabilidade ao modelo simulado construído.

A Figura 7 apresenta os valores obtidos para o tempo médio de ocupação da sala de cirurgia por especialidade médica.

A última variável a ser analisada é a taxa de ocupação das salas de cirurgia. A Figura 8 apresenta os valores obtidos pela simulação e os valores coletados (reais). Constata-se que em cinco salas de cirurgia os intervalos de confiança
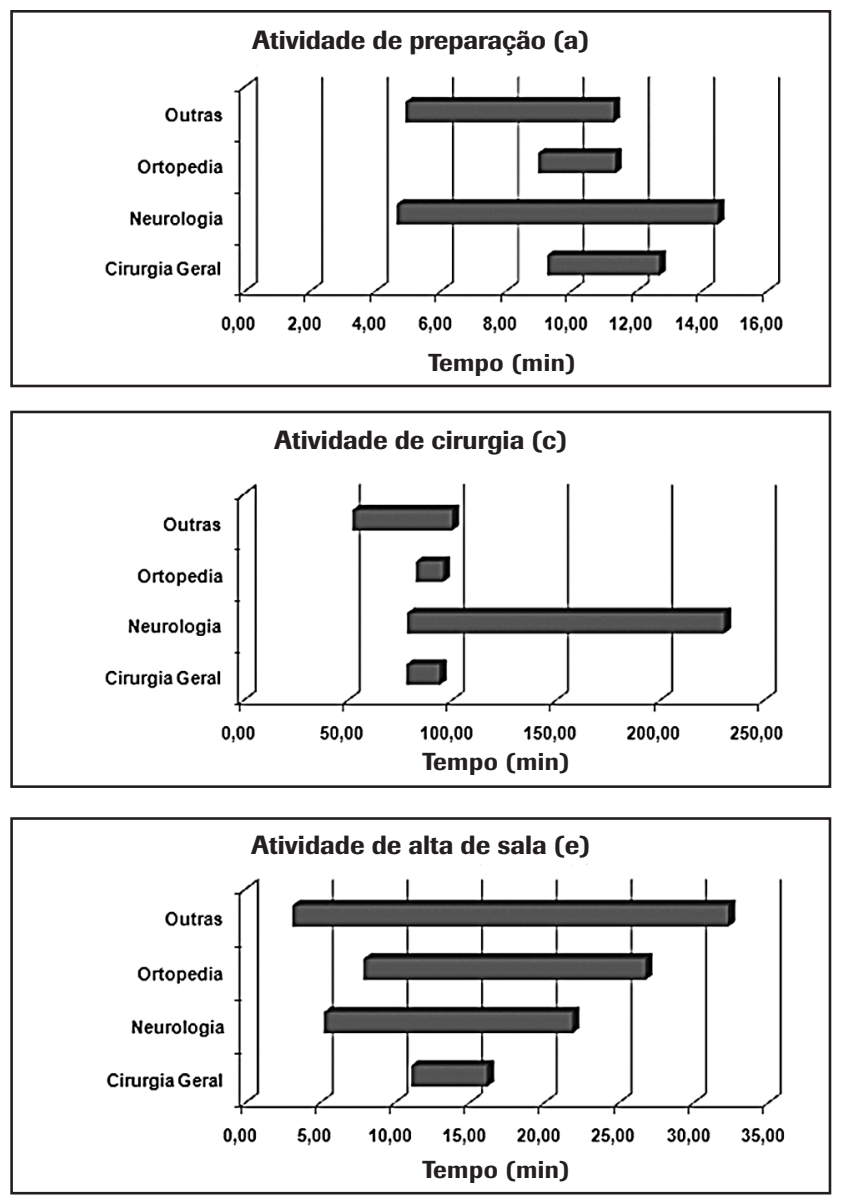
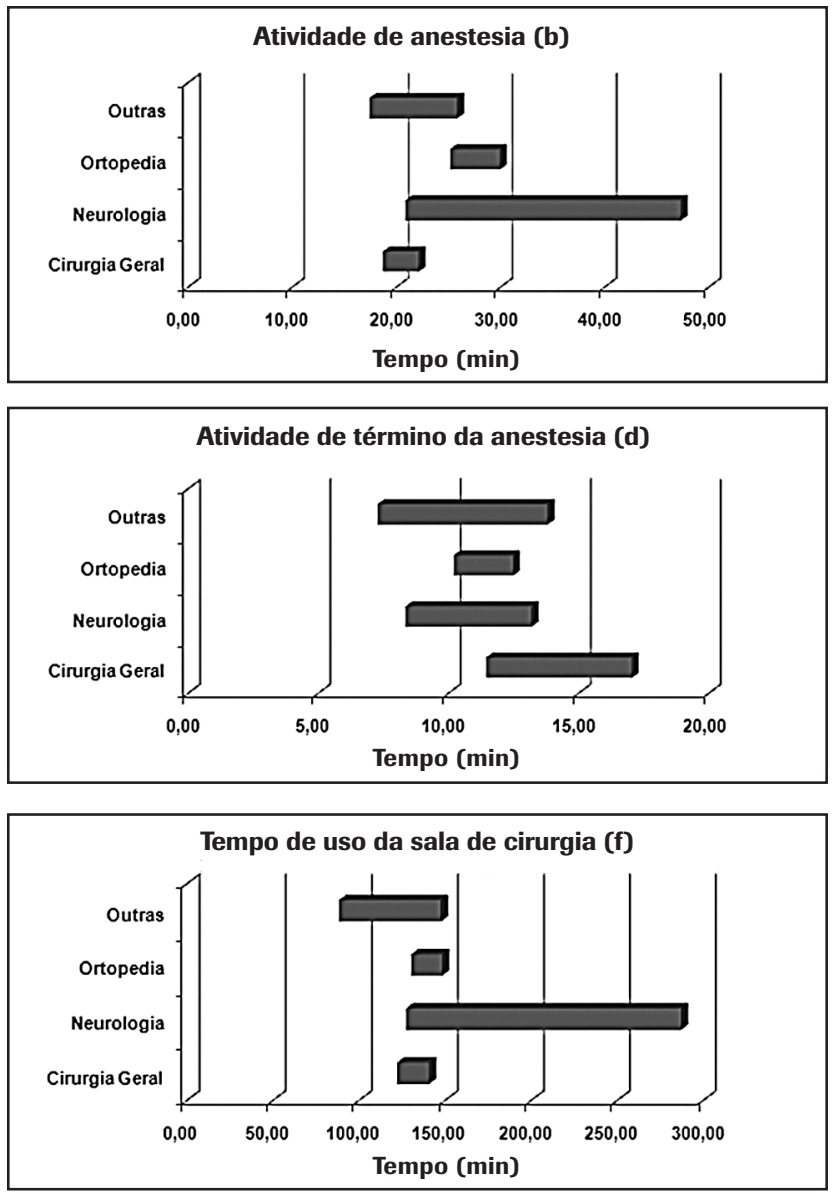

Figura 3: Tempo médio de uso de sala. 
são coincidentes. Apenas no intervalo de confiança da taxa de ocupação da sala 1 não ocorre coincidência entre os valores obtidos no cenário real e no cenário simulado. Cabe, então, efetuar uma análise mais detalhada da situação específica da sala 1.

\section{o modelo de simulação é fácil aumentar $\checkmark$ a frequência de chegada dos pacientes e,} desta forma, estimar o impacto que o aumento de demanda trará ao desempenho do centro cirúrgico.

O uso da sala de cirurgia 1, a princípio, destina-se aos procedimentos de emergência, porém o que se verifica é que esse tipo de procedimento tem prioridade no uso de qualquer sala de cirurgia e, portanto, essa norma não é necessariamente seguida. Consequentemente, não se consegue estipular uma regra lógica para a ordem de utilização das salas. Situação semelhante é relatada por Stroparo (2005), que constatou existir distorção entre a taxa de ocupação por especialidade médica do cenário real e do modelo simulado.

Analisando-se as taxas de ocupação, considerando-se as salas de cirurgia como um conjunto único (CCHUC), tanto para o modelo real como para o modelo simulado, obtêm-se os valores apresentados na Figura 9. Nesta pode-se constatar a sobreposição dos intervalos de confiança, não se podendo afirmar, portanto, que há diferença significativa entre a taxa de ocupação do cenário real com o seu respectivo cenário simulado.

Com base na comparação e análise de todas as variáveis apresentadas, conclui-se que o modelo de simulação oferece credibilidade e é um modelo representativo do sistema real, isto é, o modelo criado pôde ser validado.

Tabela 4: Expressões utilizadas nas atividades.

\begin{tabular}{|c|c|c|c|c|c|}
\hline Atividade & Especialidade & Expressão (minutos) & $\begin{array}{c}\text { Número de } \\
\text { dados usados }\end{array}$ & $\begin{array}{c}\text { Erro } \\
\text { quadrático }\end{array}$ & $\begin{array}{l}\text { Valor } p \text { correspondente } \\
\text { (p/ Chi Quadrado) }\end{array}$ \\
\hline \multirow[t]{4}{*}{ Preparação } & Cirurgia Geral & GAMMA $(11.7,1.35)$ & 191 & 0,042 & $<0,005$ \\
\hline & Neurologia $(*)$ & TRIANGULAR $(4.5,10,40.5)$ & 13 & 0,142 & $\mathrm{~N} / \mathrm{D}$ \\
\hline & Ortopedia & 0.5 + LOGNORMAL $(14.8,14.3)$ & 315 & 0,166 & $<0,005$ \\
\hline & Outras & $0.5+\operatorname{ERLANG}(7.85,2)$ & 26 & 0,151 & $<0,005$ \\
\hline \multirow[t]{4}{*}{ Anestesia } & Cirurgia Geral & $1.5+$ ERLANG $(9.46,2)$ & 257 & 0.114 & $<0,005$ \\
\hline & Neurologia & TRIANGULAR $(10,20,110)$ & 22 & 0.010 & $<0,005$ \\
\hline & Ortopedia & $0.999+$ ERLANG $(13.3,2)$ & 430 & 0.013 & $<0,005$ \\
\hline & Outras & NORMAL $(21.6,14.4)$ & 48 & 0.144 & $<0,005$ \\
\hline \multirow[t]{4}{*}{ Cirurgia } & Cirurgia Geral & 10 + GAMMA $(56.3,1.35)$ & 275 & 0,002 & 0,109 \\
\hline & Neurologia & TRIANGULAR $(20,105,870)$ & 23 & 0.235 & $<0,005$ \\
\hline & Ortopedia & $5+$ GAMMA $(54.7,1.54)$ & 470 & 0.003 & $<0,005$ \\
\hline & Outras & 10 + LOGNORMAL $(154,772)$ & 52 & 0,013 & $<0,005$ \\
\hline \multirow{4}{*}{$\begin{array}{c}\text { Término de } \\
\text { anestesia }\end{array}$} & Cirurgia Geral & $5+$ WEIBULL $(3.31,0.337)$ & 165 & 0,003 & $<0,005$ \\
\hline & Neurologia & TRIANGULAR $(4.5,10,15.5)$ & 13 & 0,316 & $N / D$ \\
\hline & Ortopedia & $1.5+$ LOGNORMAL $(9.55,8.15)$ & 298 & 0,234 & $<0,005$ \\
\hline & Outras & $4.5+36 *$ BETA $(0.259,1.29)$ & 28 & 0,141 & $<0,005$ \\
\hline \multirow[t]{4}{*}{ Alta de sala } & Cirurgia Geral & $5+$ WEIBULL $(2.81,0.319)$ & 132 & 0,001 & $<0,005$ \\
\hline & Neurologia & TRIANGULAR $(4.5,5,30.5)$ & 7 & 0,184 & $\mathrm{~N} / \mathrm{D}$ \\
\hline & Ortopedia & 4 + WEIBULL $(8.41,0.672)$ & 199 & 0,000 & $<0,005$ \\
\hline & Outras & $5+$ EXPONENCIAL (12.7) & 23 & 0,008 & $<0,005$ \\
\hline
\end{tabular}




\subsection{Simulando aumento de demanda (cirurgias) no centro cirúrgico}

No modelo de simulação desenvolvido é fácil aumentar a frequência de chegada dos pacientes no centro cirúrgico e, desta forma, estimar o impacto que o aumento de demanda trará ao desempenho do centro, isto é, na ocupação das salas cirúrgicas, nos tempos de utilização e nas quantidades de cirurgias realizadas por dia.

O cenário atual possui um tempo entre ocorrências de cirurgias que segue distribuição exponencial com média de 126 minutos (EXPO(126)) para as cirurgias de emergência e EXPO $(70,4)$ minutos para as cirurgias eletivas.
Para se analisar o aumento de demanda no centro deve-se reduzir o intervalo de tempo entre ocorrência de cirurgias. Para isto, inclui-se um fator a na expressão do tempo

Tabela 5: Quantidade de cirurgias realizadas.

\begin{tabular}{cccc}
\hline Tipo de cirurgia & Cenário & Média & Semi-intervalo \\
\hline Eletiva & Real & 10,84 & 1,99 \\
& Simulado & 12,00 & 0,69 \\
\hline \multirow{2}{*}{ Emergência } & Real & 8,23 & 1,33 \\
& Simulado & 7,00 & 0,51 \\
\hline
\end{tabular}

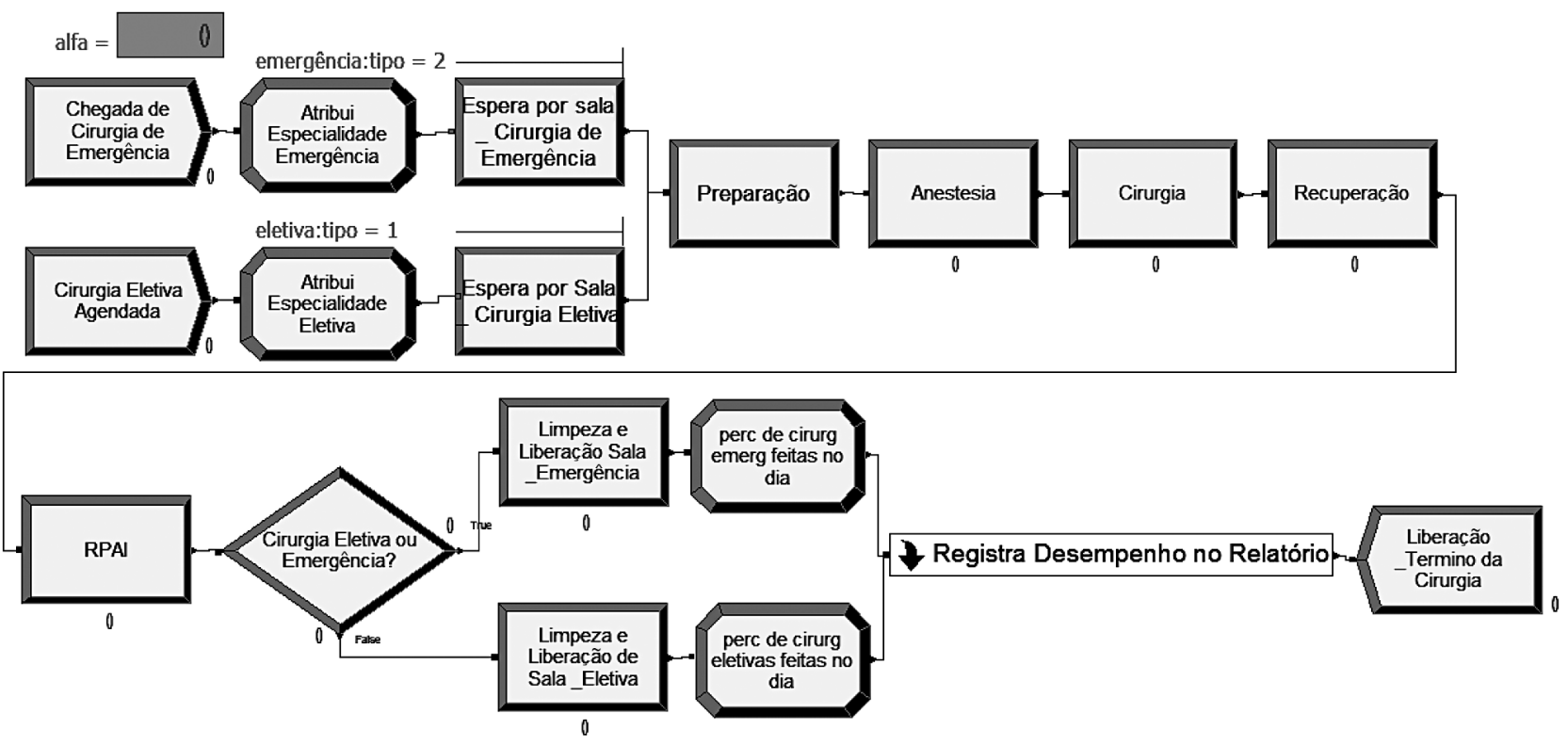

Figura 4: 0 modelo de simulação do cenário atual do CCHUC.

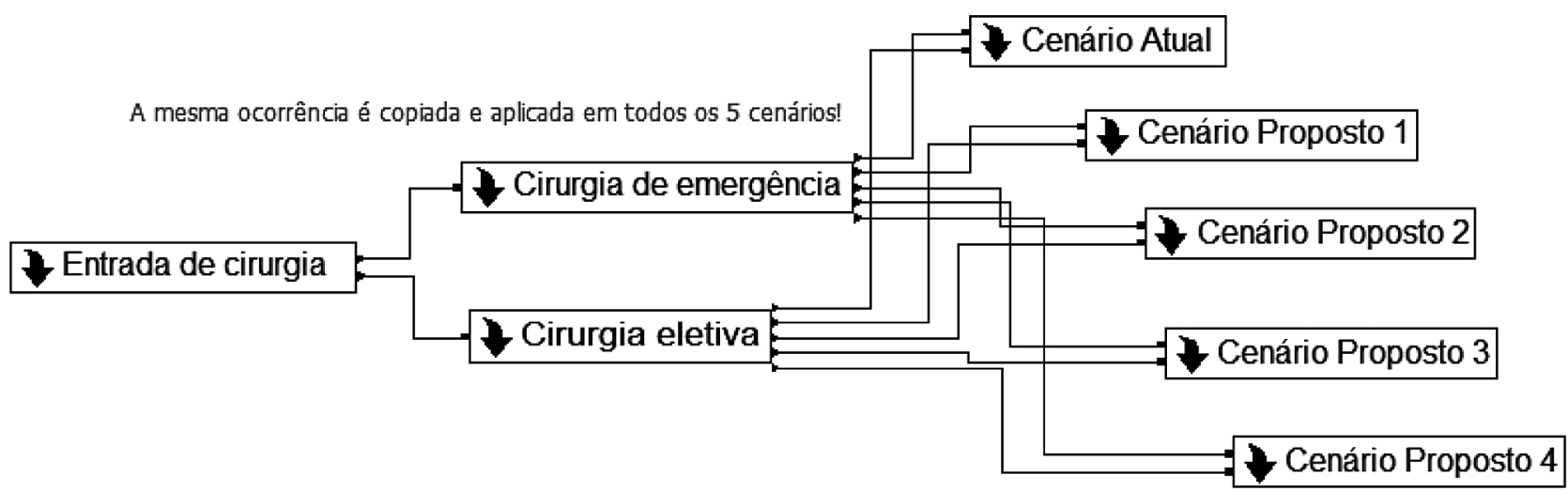

Figura 5: $1^{\circ}$ Nível hierárquico do modelo geral de simulação. 
entre cirurgias, passando-se a ter $\alpha . E X P O(126)$ para o tempo entre cirurgias de emergência e $\alpha . \operatorname{EXPO}(70,4)$ para o tempo entre cirurgias eletivas. A taxa de chegadas de cirurgias de emergência é então 1/ $\alpha . E X P O(126)$, assim, para se analisar um aumento de $50 \%$ de demanda, a nova taxa passará a ser

$\left[(1+0,50)^{\star} 1 / \operatorname{EXPO}(126)\right]=1 / 0,667^{\star} \operatorname{EXPO}(126) \rightarrow \alpha=0,6667$.

Desta forma, os quatro padrões de demanda analisados são representados como:

1. Demanda no ano de 2004: $\alpha=1$;

2. Aumento de $50 \%$ de demanda: $\alpha=0,6667$.

3. Aumento de $100 \%$ (dobro) na demanda: $\alpha=0,5$.

4. Aumento de $200 \%$ na demanda: $\alpha=0,3333$.

Os resultados das simulações (indicadores de desempenho ou KPIs) da configuração atual do centro cirúrgico para os quatro padrões de demanda considerados estão dados na Tabela 6.
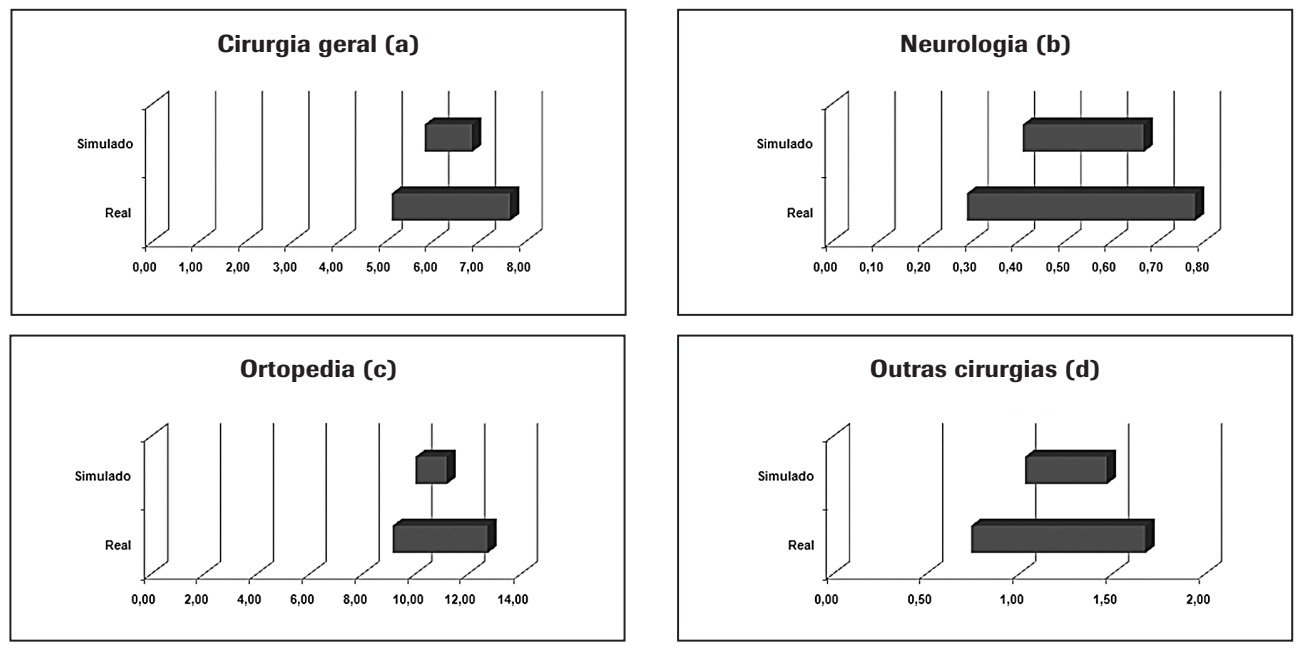

Figura 6: Quantidade de cirurgias realizadas por especialidade.
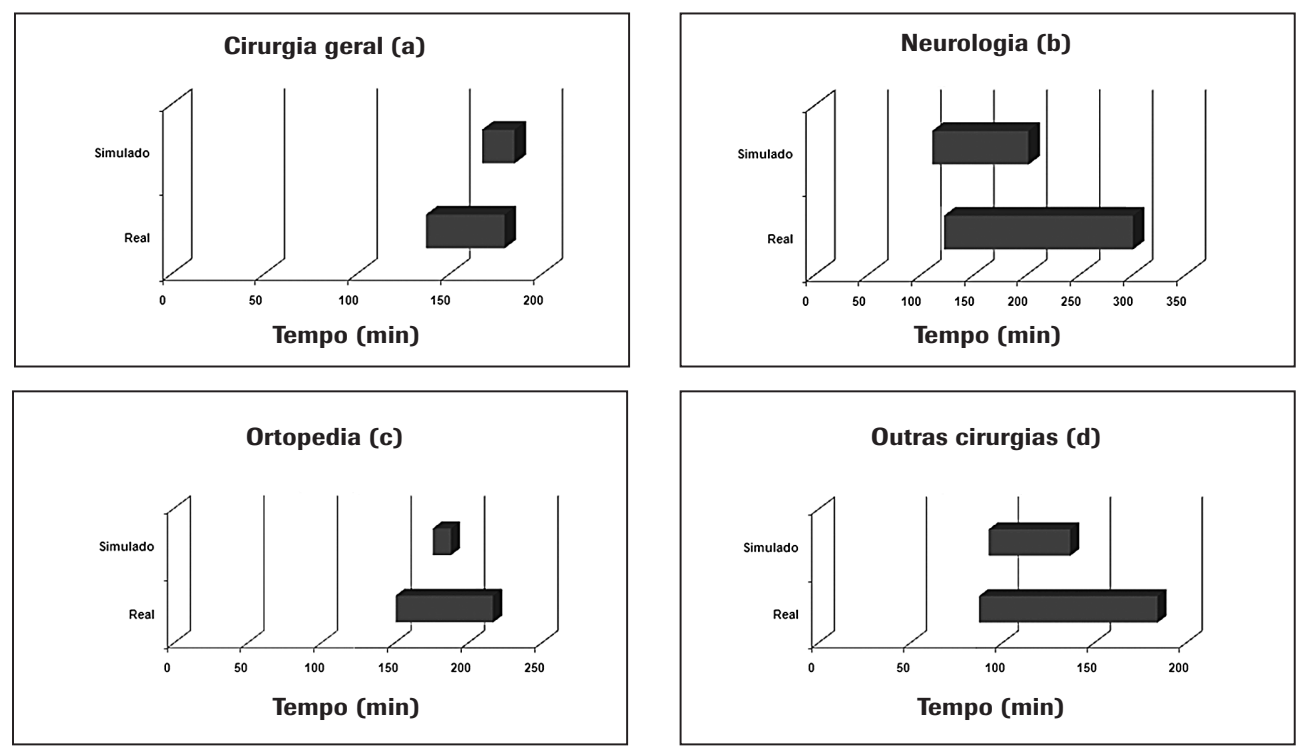

Figura 7: Tempo de ocupação de sala por especialidade médica. 
No padrão de demanda de 2004, não se espera muito tempo por uma sala cirúrgica quando ocorre uma cirurgia de emergência $\left(\mathrm{KPI}_{1}\right)$ - cerca de 5,37 minutos depois que o paciente entrou no CC. Também praticamente não há cirurgia de emergência em espera $\left(\mathrm{KPI}_{2}\right): 0,06$. A taxa de ocupação do CCHUC $\left(\mathrm{KPI}_{4}\right)$ crescerá de $56 \%$ para $89 \%$ quando a demanda for o dobro da demanda de 2004. Nesta situação, os enfermeiros, anestesistas e médicos estarão trabalhando praticamente sem parar, em ritmo frenético, durante as oito horas do seu expediente. Isto certamente não será bom para eles, mas, principalmente, não será bom para os pacientes. Assim, a situação fica ruim com um aumento de 50\% na demanda e inaceitável com mais de 100\% de acréscimo.

\section{MODELAGEM E ANÁLISE DE NOVOS CENÁRIOS PARA O CCHUC}

Quatro novos cenários para o CCHUC são propostos e
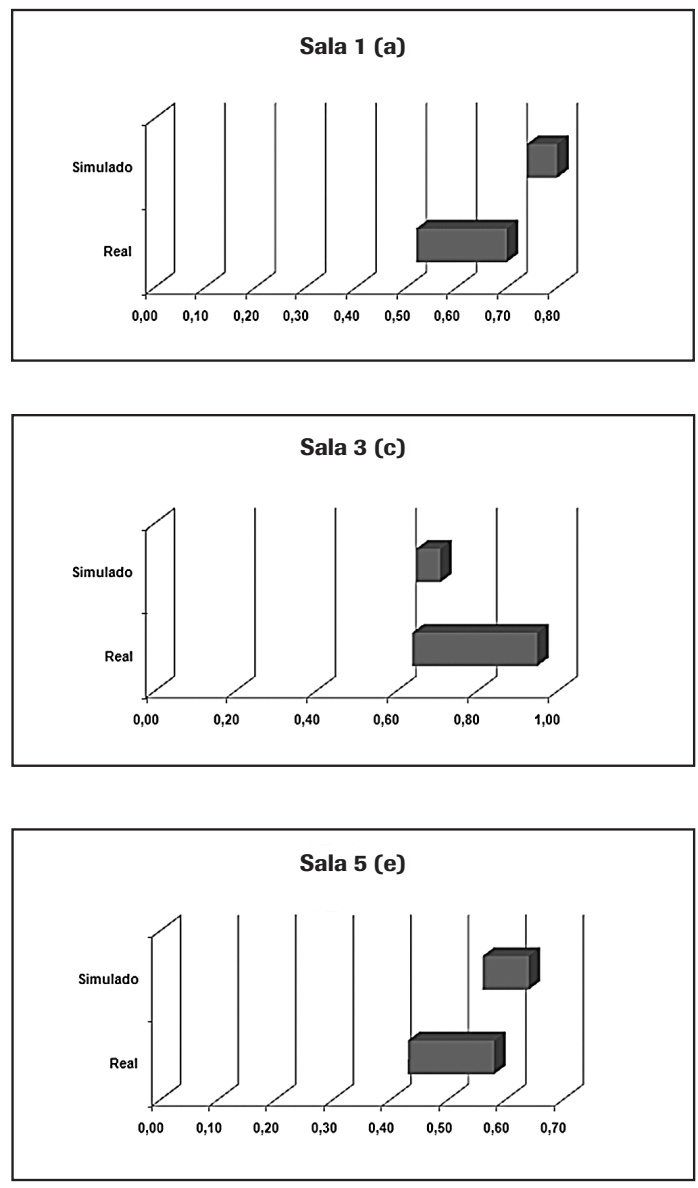

analisados por meio de simulação computacional (Seção 1). Esses cenários são criados a partir de duas alterações possíveis de serem efetuadas no atual sistema:

- Alteração no fluxo das atividades internas do CC, e

- Ampliação na quantidade de salas operatórias.

Devido aos custos financeiros, o hospital considera inicialmente somente a possibilidade de implementação dos cenários I, II ou IV.

\subsection{Alterando-se o fluxo de atividades}

A reestruturação nas etapas do fluxo de atendimento poderá ser feita através da criação de um ambiente com a instalação de leitos para a realização de atividades que na configuração atual são executadas dentro da sala de cirurgia, mas que podem ser facilmente feitas em outro local. Especificamente, considera-se que as atividades de preparação, anestesia e de alta da sala cirúrgica podem ir para outra área do centro cirúrgico, desocupando as instalações de uma sala
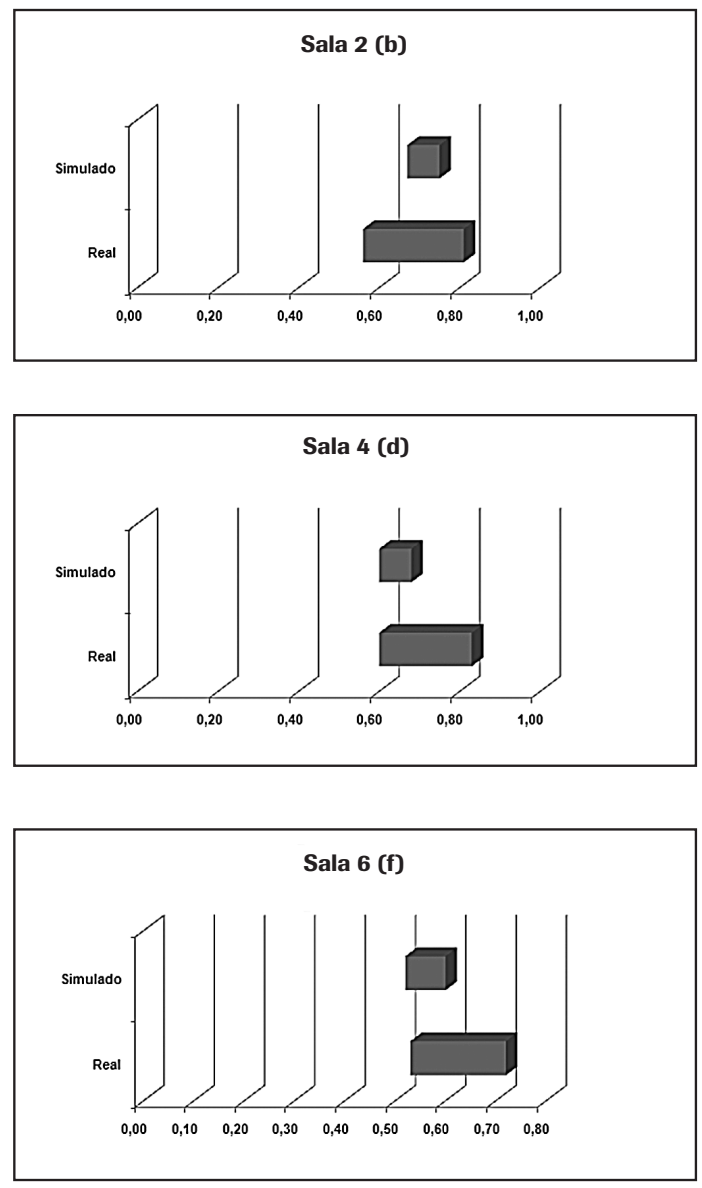

Figura 8: Taxa de ocupação das salas de cirurgia do HUC. 
de cirurgia. Permanecerão as atividades de cirurgia e término da anestesia como as únicas atividades a serem realizadas dentro da sala de cirurgia.

Essas novas salas têm um custo financeiro de implantação muito menor que o custo de implantação de uma sala de cirurgia, e por isso esta ideia é bastante atraente à direção do hospital, além de ser de fácil e rápida implementação. A capacidade de atendimento dessas novas salas é traduzida pelo número de leitos instalados. No total, o projeto prevê a instalação de quatro leitos na sala de indução anestésica, onde serão efetuadas as atividades de preparação e anestesia, e mais seis leitos na sala de RPAI, onde será realizada a fase de alta.

Permanecerá computada no tempo de ocupação da sala de cirurgia a atividade de limpeza, sendo que o término dessa etapa continuará definindo a liberação da sala para a utilização por um novo procedimento.

Em relação ao modelo original, algumas diferenças básicas serão:

a. Transferência do paciente da sala de indução anestésica para a sala de cirurgia.

b. Transferência do paciente para a sala de recuperação, quando se conclui o término da anestesia.

c. A atividade de limpeza poderá ser efetuada em paralelo com a atividade de alta de sala, pois nesse momento o paciente já deixou a sala de cirurgia.

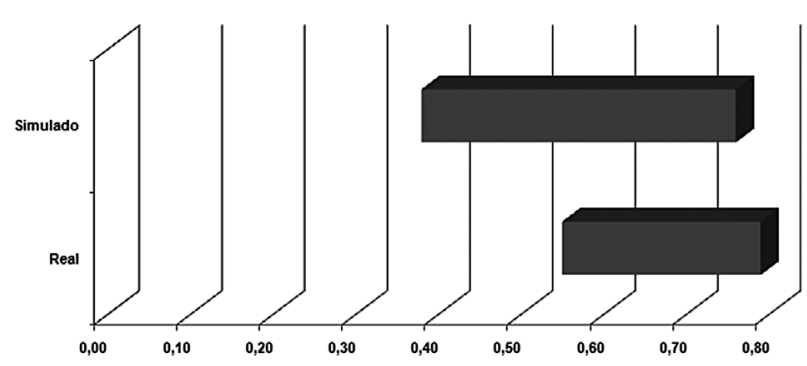

Figura 9: Taxa de ocupação do CCHUC.
A enfermeira chefe do CCHUC estimou que a duração de cada uma das atividades $a$ e $b$, acima descritas, deve ficar em torno de três minutos, nunca sendo inferior a um minuto e nem superior a cinco minutos. De acordo com Freitas Filho (2001), a distribuição teórica de probabilidade mais indicada para esse caso é a distribuição triangular, pois existe a estimativa do valor mais provável e se conhecem o limite inferior e o superior. Consequentemente, a expressão a ser utilizada é triangular - TRIA $(1,3,5)$ minutos. O modelo de simulação para os cenários com mudança no fluxo (II e IV) é dado na Figura 10.

\subsection{Resultados das simulações - identificação das melhores alternativas para o CCHUC}

A análise comparativa é feita com os dados de 2004, sem perder de vista o aumento de demanda já ocorrido e que ocorrerá ainda mais nesses próximos anos. Portanto, para fins de comparação, considera-se a situação (desempenho) de 2004 como referência, mesmo porque os indicadores neste ano eram de fato bons e foram disponíveis ao estudo. Sendo assim, um determinado indicador será considerado bom se seu valor estiver próximo (ou for melhor que) ao valor de comparação (2004). A Tabela 7 resume os resultados das simulações para todos os cenários analisados frente aos diferentes padrões de demanda possíveis.

Portanto, qual deve ser a melhor alteração no centro cirúrgico de forma a se ter o tempo de espera por sala cirúrgica em torno de 5,4 minutos (como era em 2004)? Para hoje $(\alpha=0,667)$, a resposta seria implantar a configuração II, III ou IV. Entretanto, um projeto de expansão hospitalar deve considerar um aumento de demanda para, pelo menos, três anos à frente. Desta forma, deve-se pensar em um aumento de demanda total de, pelo menos, $100 \%$ a partir de 2004 (aprox. 50\% a partir de 2007). Pensando-se em uma estimativa de demanda para 2010/2011, as análises comparativas serão feitas principalmente considerando-se um aumento de $100 \%$ na demanda.

De todos os cenários propostos, é claro que o cenário III

Tabela 6: Desempenho da configuração do atual CCHUC frente aos diferentes padrões de demanda.

\begin{tabular}{ccccc}
\hline & $\alpha=1,0$ & $\alpha=0,667$ & $\alpha=0,5$ & $\alpha=0,333$ \\
\hline$K P I_{1}$ & $5,37 \pm 1,73$ & $18,06 \pm 2,37$ & $28,89 \pm 2,48$ & $53,98 \pm 5,39$ \\
$K P I_{2}$ & $0,06 \pm 0,02$ & $0,26 \pm 0,04$ & $0,52 \pm 0,05$ & $1,46 \pm 0,21$ \\
$K_{3}$ & $173,01 \pm 4,10$ & $202,24 \pm 7,69$ & $240,37 \pm 7,39$ & $266,45 \pm 6,97$ \\
$K_{3} I_{4}$ & $0,56 \pm 0,19$ & $0,77 \pm 0,18$ & $0,89 \pm 0,14$ & $0,95 \pm 0,06$ \\
$K$ & 91,95 & 86,49 & 84,52 & 78,31 \\
$K_{5}$ & 86,08 & 76,92 & 55,68 & 30,55 \\
\hline
\end{tabular}


(aumento do número de salas cirúrgicas de seis para dez com alteração no fluxo) dará as melhores respostas. Entretanto, como anteriormente dito, este cenário requererá os maiores investimentos financeiros. Portanto, o que se deseja realmente é saber qual dentre os cenários I, II e IV melhor atenderá o aumento de $100 \%$ na demanda.

Começando pelo indicador de desempenho mais importante, tempo de espera por sala cirúrgica, a situação no cenário atual (i.é, em 2004) é razoável, tendo o paciente que esperar em torno de 5,4 minutos para iniciar seu procedimento cirúrgico. É importante lembrar que outros tempos de atraso ou espera (registro de entrada, triagem, etc.) não estão incorporados neste tempo. Imaginando-se que há um aumento de demanda em torno de 15 a $20 \%$ ao ano, de 2004 até hoje já deve ter ocorrido cerca de $50 \%$ de aumento. Se nenhuma melhoria foi feita desde 2004, um paciente já deve esperarar aproximadamente 18 minutos para iniciar seu procedimento cirúrgico.

Ainda no que diz repeito ao tempo de espera por sala cirúrgica, as melhores alternativas de implantação continuam sendo as propostas II, III e IV, entretanto, o cenário IV apresenta um tempo de espera $24 \%$ menor que o cenário II. Pode-se, também, excluir da comparação o cenário I, pois para o aumento de $100 \%$ na demanda, $o$ tempo de espera por sala cirúrgica passa a ser de 23 minutos, considerado inaceitável pelo CCHUC.

Para um aumento de demanda de $200 \%$, i.é, demanda esperada em 2015/20016, o único cenário que traria um bom desempenho ao centro (com relação ao tempo de espera por sala cirúrgica) seria o cenário III. O cenário proposto III também manteria o tempo médio total de execução de cirurgia (eletivas e de emergência) próximo aos valores atuais. Nenhum outro indicador, de nenhum outro cenário proposto, estará bom nessa data. Sugere-se, portanto, que o hospital faça um planejamento estratégico para 2015/2016 considerando outras ampliações - possivelmente um número bem maior de salas de cirurgia aliado ao rearranjo dos fluxos.

Com relação ao $\mathrm{KPI}_{2}$ (Número de cirurgias de emergência na fila de espera por sala cirúrgica), estatisticamente não há diferença significativa entre o cenário II e o cenário IV. Entretanto, o cenário II responde de forma semelhante ao atual cenário, enquanto que o Cenário IV responde pior que o cenário atual (possivelmente haverá maior fila de espera. Mas veja que os valores, em qualquer um dos cenários, é próximo a zero $(0,01$ e 0,02$)$, então, na prática, praticamente não haverá fila em qualquer um desses dois cenários.) .

Com relação ao tempo médio total de execução de cirurgia (eletivas e de emergência) - $\mathrm{KPI}_{3}$ - o cenário IV responde muito melhor que o cenário II e muito melhor que a atual situação (2004). O tempo médio de execução de cirurgia neste cenário é inclusive estatisticamente semelhante ao desempenho do cenário III (que, como dito anteriormente, é o melhor possível).

Com relação à ocupação média das salas de cirurgia (KPI4), no cenário atual (2004) as salas estão ocupadas $56 \%$ do tempo. Com o aumento de $100 \%$ na demanda, esta ocupação passaria a ser de $89 \%$, inaceitável na prática. No cenário II proposto, a ocupação média deve ficar em torno de $74 \%$ e no cenário IV ficará em aproximadamente $65 \%$. Novamente o cenário IV apresenta uma resposta muito melhor que a do cenário II e mais próxima à situação atual. Isto se deve simplesmente ao fato de que algumas atividades saíram da sala cirúrgica e foram para as salas RPAI.

\section{Nenhum dos trabalhos pesquisados que utilizaram simulação computacional no setor hospitalar considerou tantos indicadores de desempenho nas suas análises.}

Os indicadores "\% de cirurgias de emergências iniciadas e terminadas no intervalo 6:00-22:00" $\left(K^{\prime} I_{5}\right)$ e "\% de cirurgias eletivas iniciadas e terminadas no intervalo 6:00-22:00" $\left(K P I_{6}\right)$ não são indicadores tão importantes quanto os dois primeiros examindados, mas merecem algumas observações. Quanto mais cirurgias terminam até às 22:00 horas, melhor para os que trabalham no hospital, principalmente para os médicos, os quais muitas vezes precisam de ir para outros consultórios e hospitais. Para as consultas agendadas, também é importante que se possa ter o procedimento cirúrgico no horário e duração esperados. Claro que as cirurgias de emergência têm preferência (e isso foi considerado nos modelos de simulação), mas às vezes cirurgias eletivas precisam ser reagendadas ou são atrasadas. Mas se estas puderem iniciar e terminar no prazo esperado, melhor para todos. O atual cenário apresenta $92 \%$ das cirurgias de emergência iniciando e terminando até às 22 horas. Nos cenários II e IV, esses valores são um pouco menores (87\% e $88 \%$, respectivamente). Novamente o cenário IV responde melhor que o cenário II, de forma parecida ao cenário III. O cenário I novamente gerou a pior resposta dentre os cenários propostos.

O cenário atual apresenta $86 \%$ das cirurgias agendadas (eletivas) terminando antes das 22 horas; no cenário II serão $82 \%$; e no cenário IV, quase $85 \%$. Novamente, o cenário IV, 
responde melhor que o cenário II, ficando próximo inclusive do cenário III.

Vê-se, portanto, que o cenário IV gera um melhor desempenho com relação a todos os indicadores de desempenho do centro cirúrgico. Mesmo com um custo de implantação um pouco maior que o custo necessário para o cenário II, o hospital deve restruturar as atividades internas dos procedimentos cirúrgicos e deve construir duas novas salas cirúrgicas (cenário IV) a fim de poder lidar eficientemente com o aumento de demanda esperado.

\section{COMENTÁRIOS FINAIS E SUGESTÕES PARA TRABALHOS FUTUROS}

O Hospital Universitário Cajuru sabe que para mater a qualidade do serviço oferecido à comunidade da região precisa expandir rapidamente a capacidade do seu centro cirúrgico. Várias alternativas existem, mas, como em tudo, os recursos financeiros são limitados e devem ser investidos com sabedoria. Dentre as alternativas analisadas para melhoria do centro, considerou-se uma restruturação das atividades do procedi-
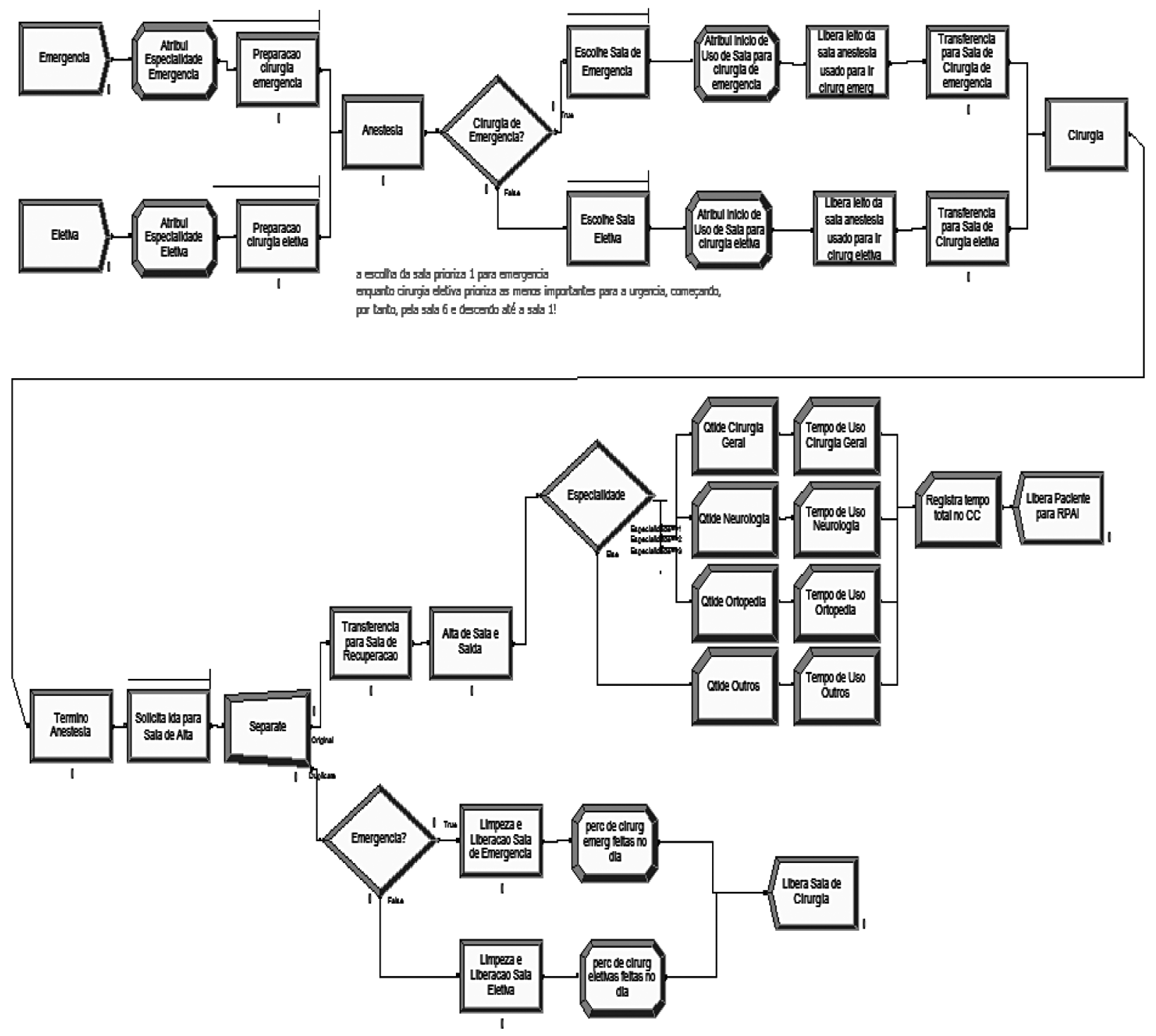

Figura 10: Modelo de simulação com alteração no fluxo 
mento cirúrgico e aumento do número de salas de cirurgia. A primeira alternativa basicamente tira de dentro da sala cirúrgica alguns procedimentos, transferindo-os para outras salas. Estas salas também requerem investimento, principalmente em leitos, mas são incomparavelmente menores que os necessários para construção de salas cirúrgicas. Com relação ao aumento do número de salas, o ideal seria se construir mais quatro salas, mas, devido aos limitados recursos, talvez apenas duas salas sejam possíveis de ser adquiridas.

Este projeto analisou os principais cenários de expansão que podem ser rapidamente aplicados no CCHUC. Para validação dos modelos de simulação desenvolvidos e para comparação de desempenho entre os diversos cenários considerados, utilizaram-se vários indicadores, tais como

Tabela 7: Desempenho do CCHUC frente aos diferentes padrões de demanda.

\begin{tabular}{|c|c|c|c|c|c|}
\hline \multirow[b]{2}{*}{ Indicador de desempenho } & \multirow[b]{2}{*}{ Cenário } & \multicolumn{4}{|c|}{ Padrão de demanda } \\
\hline & & $\alpha=1,0$ & $\alpha=0,6667$ & $\alpha=0,5$ & $\alpha=0,3333$ \\
\hline \multirow{5}{*}{$\mathrm{KPI}_{1}$} & Atual & $5,37 \pm 1,73$ & $18,06 \pm 2,37$ & $28,89 \pm 2,48$ & $53,98 \pm 5,39$ \\
\hline & Prop. I & $1,05 \pm 0,54$ & $9,77 \pm 2,14$ & $23,26 \pm 3,43$ & $37,21 \pm 2,21$ \\
\hline & Prop. II & $0 \pm 0$ & $0,95 \pm 0,43$ & $4,85 \pm 1,08$ & $17,22 \pm 1,60$ \\
\hline & Prop. III & $0 \pm 0$ & $0,13 \pm 0,14$ & $0,7 \pm 0,30$ & $4,49 \pm 0,82$ \\
\hline & Prop. IV & $0,3 \pm 0,33$ & $1,57 \pm 0,96$ & $3,69 \pm 0,96$ & $14,91 \pm 1,43$ \\
\hline \multirow[t]{5}{*}{$\mathrm{KPI}_{2}$} & Atual & $0,06 \pm 0,02$ & $0,26 \pm 0,04$ & $0,52 \pm 0,05$ & $1,46 \pm 0,21$ \\
\hline & Prop. I & $0,01 \pm 0,01$ & $0,13 \pm 0,03$ & $0,39 \pm 0,06$ & $0,87 \pm 0,06$ \\
\hline & Prop. II & $0 \pm 0$ & $0,01 \pm 0,01$ & $0,09 \pm 0,02$ & $0,45 \pm 0,05$ \\
\hline & Prop. III & $0 \pm 0$ & $0 \pm 0$ & $0,01 \pm 0,01$ & $0,12 \pm 0,02$ \\
\hline & Prop. IV & $0 \pm 0$ & $0,02 \pm 0,01$ & $0,07 \pm 0,02$ & $0,37 \pm 0,04$ \\
\hline \multirow[t]{5}{*}{$\mathrm{KPI}_{3}$} & Atual & $173,01 \pm 4,10$ & $202,24 \pm 7,69$ & $240,37 \pm 7,39$ & $266,45 \pm 6,97$ \\
\hline & Prop. I & $159,9 \pm 3,26$ & $174,2 \pm 4,94$ & $195,88 \pm 7,79$ & $246,79 \pm 7,96$ \\
\hline & Prop. II & $168,86 \pm 3,69$ & $167,66 \pm 2,86$ & $177,22 \pm 4,15$ & $212,42 \pm 6,24$ \\
\hline & Prop. III & $160,61 \pm 3,83$ & $159,14 \pm 2,93$ & $163,96 \pm 2,60$ & $173,56 \pm 3,96$ \\
\hline & Prop. IV & $161,03 \pm 4,10$ & $163,51 \pm 3,86$ & $164,03 \pm 3,36$ & $199,23 \pm 6,23$ \\
\hline \multirow[t]{5}{*}{$\mathrm{KPI}_{4}$} & Atual & $0,56 \pm 0,19$ & $0,77 \pm 0,18$ & $0,89 \pm 0,14$ & $0,95 \pm 0,06$ \\
\hline & Prop. I & $0,46 \pm 0,11$ & $0,67 \pm 0,07$ & $0,82 \pm 0,04$ & $0,92 \pm 0,02$ \\
\hline & Prop. II & $0,39 \pm 0,14$ & $0,56 \pm 0,11$ & $0,74 \pm 0,06$ & $0,91 \pm 0,02$ \\
\hline & Prop. III & $0,28 \pm 0,13$ & $0,40 \pm 0,13$ & $0,54 \pm 0,10$ & $0,73 \pm 0,05$ \\
\hline & Prop. IV & $0,35 \pm 0,13$ & $0,50 \pm 0,11$ & $0,65 \pm 0,07$ & $0,84 \pm 0,03$ \\
\hline \multirow[t]{5}{*}{$\mathrm{KPI}_{5}$} & Atual & 91,95 & 86,49 & 84,52 & 78,31 \\
\hline & Prop. I & 91,96 & 87,55 & 84,65 & 78,18 \\
\hline & Prop. II & 91,96 & 87,65 & 86,6 & 82,81 \\
\hline & Prop. III & 92,00 & 89,61 & 88,06 & 84,17 \\
\hline & Prop. IV & 92,19 & 89,65 & 88,12 & 82,88 \\
\hline \multirow[t]{5}{*}{$\mathrm{KPI}_{6}$} & Atual & 86,08 & 76,92 & 55,68 & 30,55 \\
\hline & Prop. I & 87,93 & 85,09 & 76,74 & 53,88 \\
\hline & Prop. II & 88,5 & 85,97 & 81,94 & 65,65 \\
\hline & Prop. III & 89,16 & 86,28 & 86,03 & 80,54 \\
\hline & Prop. IV & 88,29 & 88 & 84,69 & 72,62 \\
\hline
\end{tabular}


quantidade de cirurgias realizadas por tipo, quantidade de cirurgias realizadas por especialidade, tempo de ocupação de sala por especialidade, taxa de ocupação média das salas cirúrgicas, tempos de espera e percentual de término da cirurgia até as 22 horas. Nenhum dos trabalhos pesquisados que utilizaram simulação computacional no setor hospitalar considerou tantos indicadores de desempenho nas suas análises.

Na comparação dos cenários simulados, verificou-se que os modelos propostos oferecem amplas vantagens em relação ao presente cenário. Entretanto, as análises foram além da situação de 2004 e consideram aumentos de demanda na ordem de $50 \%, 100 \%$ e $200 \%$ em relação à demanda deste ano. Com relação a um aumento de $100 \%$ na demanda, verificou-se que o cenário I não apresentará desempenho satisfatório. O cenário III dará a melhor resposta, mas exigirá um alto investimento financeiro, mas sua implantação está fora de cogitação neste momento. Fez-se, portanto, uma análise detalhada somente entre os cenários II e IV.
Pôde-se ver claramente que o cenário IV (construção de duas novas salas cirúrgicas aliadas à restruturação dos fluxos operatórios) trará melhores benefícios ao hospital do que o cenário II (construção de quatro salas cirúrgicas sem restruturação de fluxo), além de ter um custo financeiro menor.

Vários outros projetos de pesquisa podem dar continuidade a este trabalho. Pode-se por exemplo, incluir outros processos existentes em um centro cirúrgico. Pode-se incluir os processos fora do centro, como recepção e triagem. Análises futuras podem considerar recursos de pessoal (médicos e enfermeiros, por exemplo), equipamentos e materiais utilizados no centro. Pode-se também incluir uma análise de custos financeiros envolvidos no processo e custos para implantação dos novos cenários analisados, visando dar um melhor suporte às decisões a serem feitas.

Além disso, este projeto mostrou também que ferramentas baseadas em simulação computacional podem (devem?) ser utilizadas nestes tipos de projetos.

\section{Artigo recebido em 06/11/2007 Aprovado para publicação em 26/03/2009}

\section{REFERÊNCIAS}

ABEL-SMITH, B. The control of health care costs and health reform in the European Community. In As reformas dos sistemas de saúde, atas do IV Encontro Nacional da APES. Lisboa: Associação Portuguesa de Economia da Saúde, 1996. p. 9-25.

BARNES, C. D.; QUIASON, J. L. Success stories in simulation in health care. Winter Simulation Conference, 1997. Disponível em: http://www. informs-cs.org/wscpapers.html. Acesso em: 10 jul. 2004.

BARROS, P. P.; SENA, C. Quanto maior melhor? Redimensionamento e economias de escala em três hospitais portugueses. 1998. Universidade de Lisboa.

BLASAK, R. E.; ARMEL, W. S.; STARKS, D. W.; HAYDUK, M. C. The use of simulation to evaluate hospital operations between the emergency department and a medical telemetry unit. Winter Simulation Conference, 2003. Disponível em: http://www.informs-sim.org/wsc03papers/244. pdf . Acesso em: 10 jul. 2004

BORBA, G. S.; RODRIGUES, L. H. Pesquisa conhecimento e viabilidade da utilização de simulação computacional nos hospitais da região metropolitana de Porto Alegre. 1998a. Disponível em: http://www.read.adm.ufrgs. br/read08/artigo/borba1.doc. Acesso em: 19 dez. 2002.

BORBA, G. S.; RODRIGUES, L. H. Simulação computacional aplicada a sistemas hospitalares. Revista Eletrônica de Administração da UFRGS, 1998b. Disponível em: http://www. read.adm. ufrgs.br/read08/artigo/borba2.htm. Acesso em: 19 dez. 2002.

BRADY, T. F. Emergency management:Capability analysis of critical incident response. Winter Simulation Conference, 2003. Disponível em: http://www.informs-cs.org/wscpapers.html. Acesso em: 10 jul. 2004.
CARDOEN, B.; DEMEULENEESTER, E. Evaluating the capacity of clinical pathways through discrete-event simulation (white paper). 2007. Katholieke Universiteit Leuven, Faculty of Economics and Applied Economics, Department of Decision Sciences and Information Management, Naamsestraat 69 B-3000 Leuven, Belgium. Link: http://www.econ.kuleuven.be/fetew/ pdf_publicaties/KBI_0712.pdf. Acesso em: set. 2007.

DENTON, B. T.; RAHMAN, A. S.; NELSON, H.; BAILEY, A. C. Simulation of a multiple operating room surgical suite. Proceedings of the 2006 Winter Simulation Conference. L. F. Perrone, F. P. Wieland, J. Liu, B. G. Lawson, D. M. Nicol, and R. M. Fujimoto, eds. 2006.

FREITAS F.; PAULLO J. DE. Introdução à modelagem e simulação computacional. Florianópolis: Visual Books, 2001. 
HUC - Hospital Universitário Cajuru. Regimento do Centro Cirúrgico do Hospital Universitário Cajuru. Curitiba, 2001.

HUC - Hospital Universitário Cajuru. Unidade gerencial básica: Centro Cirúrgico. Curitiba, 2002.

LAW, A. M.; KELTON, W. D. Simulation Modeling \& Analysis. 2. ed. McGraw-Hill International Editions, 1991.

LOWERY, J. C.; DAVIS, J. A. Determination of operating room requirements using simulation. Winter Simulation Conference, 1999. Disponível em: http://www.informs-cs.org/wscpapers.html. Acesso em: 10 jul. 2004.
MILLER, M. J.; FERRIN, D. M.; SZYMANSKI, J. M. Simulating Six Sigma improvement ideas for a hospital emergency department. Winter Simulation Conference, 2003. Disponível em: http://www.informs-cs.org/ wscpapers.html. Acesso em: 10 jul. 2004.

OSIDACH, V. Z.; FU, M. C. Computer simulation of a mobile examination center. Winter Simulation Conference, 2003. Disponível em: http://www.informs-cs.org/wscpapers.html. Acesso em: 10 jul. 2004.

PERDONÁ, G. C.; MONTEIRO, R. A.; VIOLA, D. N.; YAZLLE, J. S. R. Simulação Aplicada à Administração Hospitalar. 2003. Disponível em: http://www.avesta.com.br/anais/dados/ trabalhos/186.pdf. Acesso em: 7 jul. 2004.
RAMIS, F. J.; PALMA, J. L.; BAESLER, F. F. The use of simulation for process improvement at na ambulatory surgery center. Winter Simulation Conference, 2001. Disponível em: http://www. wintersim.org/prog01.htm. Acesso em: 10 jul. 2004.

SANCHES, S. M.; FERRIN, D. M.; OGAZON, T.; SEPÚLVEDA, J. A. Emerging issues in healthcare simulation. Winter Simulation Conference, 2000. Disponível em: http://www.informs-cs.org/wscpapers.html. Acesso em: 10 jul. 2004.

STROPARO, J. R. Estudo da taxa de ocupação do centro cirúrgico através da modelagem e simulação de sistemas. Dissertação de Mestrado - PUCPR - 2005.

\section{AGRADECIMENTOS}

Os autores agradecem à Pontifícia Universidade Católica do Paraná (PUCPR) e ao Conselho Nacional de Desenvolvimento Científico e Tecnológico (CNPq) pelo apoio financeiro e aos funcionários do Centro Cirúrgico do Hospital Unviersitário Cajuru pela prestatividade e auxílio na execução deste projeto.

\section{SOBRE OS AUTORES}

\section{Élcio Douglas Joaquim}

Tangram Sistemas Empresariais Ltda.

End.: Rua Acyr Guimarães, 436 - Curitiba - PR - 80.220-240

Tel.: (41) 3566-6213

E-mail: elcio.joaquim@brturbo.com.br

\section{Guilherme Ernani Vieira}

Pontifícia Universidade Católica do Paraná

Programa de Pós-graduação em Engenharia de Produção e Sistemas

$2^{\circ}$ andar - Bloco 3 - Parque Tecnológico

End.: Imaculada Conceição 1155, Curitiba - PR - 80.215-901

Tel.: (41) 3271-2473 Fax: (41) 3271-1345

E-mails: gui.vieira@pucpr.br / guilherme@pq.cnpq.br 